\title{
Genetics of Castes and Tribes of India: Taste Sensitivity
}

\author{
M. K. Bhasin \\ Department of Anthropology, University of Delhi, Delhi 110 007, India
}

KEYWORDS Biological variation; genetic trait; ethnic groups; phenylthiocarbamide

\begin{abstract}
In the present paper and attempt has been made to study the distribution differences in tasting ability in India, which are analysed in relation to ecological, socio-economic and linguistic factors. Among population groups of India, the frequency of the taster allele $(T)$ is 0.457 (varies from 0.108 to 0.912 ). It is present in high frequency among scheduled caste and in low frequency among community. Among the different zones, it is present in high frequency in population groups of Islands followed by North and South India and in low frequency in West and Central India, where it is low in scheduled tribe groups in general. In Himalayan region, its frequency is high (0.533) as compared to non-Himalayan region (0.426). From Eastern Himalayan region the frequency of allele $T$ is low $(0.538)$ among populations with Mongoloid affinities as compared to the Mongoloid populations of East Asia and Southeast Asia (0.70) which may be due to high frequency of goiter in this region. High frequency is observed in Austro-Asiatic and Tibeto-Chinese families than in Dravidian and Indo-European families.
\end{abstract}

\section{INTRODUCTION}

The importance of the ability to taste phenylthiocarbamide (P.T.C.) was realized long back in 1932 by Fox, when he failed to make any taste out of it, while his colleague found it to be bitter. Thereafter, Synder (1932) showed that the inheritance of the ability to taste P.T.C. was dependent on a single autosomal dominant gene. The simple model is, however, complicated by other factors like sex (Blakeslee and Salmon 1931; Falconer 1947; Mohr 1951; Pons 1955), age (Harris and Kalmus 1949a; Mohr 1951; Kalmus 1958; Glanville et al. 1964); the presence or absence of the saliva of the subject (Cohen and Ogden 1949) and also the strength of the test solution (Harris and Kalmus 1949b). These factors invariably modify the phenotypic expression and their genetic relationships to tasting and non-tasting alleles are not yet determined. It has been suggested that there are modifying genes at other loci (Stern 1960; Blumberg 1961) or otherwise, the penetrance of the two alleles may vary (Boyd 1950; Kalmus, 1958). Incomplete dominance and penetrance of the taster was suggested by Das (1958) and he estimated the degree of penetrance of taster gene to be 80 per cent, but it may be less (Das 1966). He further added that as it is most likely that the variation in the expression of the taster allele including its complete suppression could be due to extra-genic factors, the degree of penetrance might be different in different peoples, places, ages etc.

Postal Address: M. K. Bhasin, B-2 (GF), South City II Gurgaon 122 002, Haryana, India
There are various methods to distinguish tasters from non-tasters (Fox 1932; Parr 1934; Blakeslee and Salmon 1935; Boyd and Boyd 1937; Hartman 1939; Harris and Kalmus 1949a) but the sorting technique with serial dilutions of Harris and Kalmus (1949a) is widely used with minor modifications because of its superiority in discerning the threshold of the individual with near perfection.

Today, it has been established beyond doubt that the ability to taste P.T.C. exhibits a strong dimorphism in human populations. The above factors which modify the actual response itself, additional researches have brought to light a number of relationships to this polymorphism, the most prominent being the ties of the thyroid, as well as its activity as a goitrogen (Harris and Kalmus 1949b). A number of studies have shown an excess of non-tasters among individuals having adenomatous goiter (Harris et al. 1949; Kitchin et al. 1959; Azevedo et al. 1965) and in addition to this, it was found that athyreotic cretins were significantly more likely to be non-tasters than normal controls (Shepard and Gartler 1960; Frazer 1961). Non-tasters have also more susceptibility to dental caries (Chung et al. 1964) and diabetes mellitus (Terry and Segall 1947; Terry 1950).

Some more reports are also available regarding the association of non-tasters with diseases (Saldanha 1956; Beiguelman 1964; Brachtel and Walter 1974; Mourao and Salzano 1978); such associations remain merely reports, and detailed work would be needed to advance further comments in this direction. Similarly, no specific relationship exists regarding the association of 
the ability to taste P.T.C. with the change of age, sex and social habits, viz., smoking, dietary habits (Blakeslee and Salmon 1935; Hartman 1939; Falconer 1947; Akesson 1959). For critical review on this subject see Jörgensen (1969).

The frequency of the taster allele $T$ is about 0.50 among European populations. Among Southwest Asian populations it varies from 0.43 to 0.75. Among Mongoloid populations of East Asia and Southeast Asia the frequency of allele $T$ is very high (about 0.70 , ranges from 0.55 to $0.95)$. The frequency among Tibetans varies from 0.62 to 0.67 . Among Africans also the frequency is high, albeit less than Mongoloids (Mourant et al. 1976; Roychoudhury and Nei 1988).

\section{IDENTIFY AND DISTINGUISH THE PEOPLE}

For the biogenetical study of the people of India, researchers have generally used the following criteria to identify and distinguish the people: 1. Regional Groups, 2. Ethnic Groups, 3. Linguistic Groups, and 4. Religious Groups.

It should, however, be kept in mind that these are the convenient units of study, although there are significant levels of overlapping between them. For example, an occupational group pursuing traditional job inhabits a region, shares religion with other categories, belongs to one or the other language group and has an aggregation of ethnic properties. But in the human population genetic studies, out of these criteria one is chosen (Bhasin, 1988).

In the present study an attempt has been made to analyse the above mentioned biogenetical traits into 1. Regional Groups, 2. Ethnic Groups, 3. Traditional Occupational Groups and 4. Linguistic Groups (For details see Bhasin et al. 1994; Bhasin and Walter 2001, 2002; Bhasin 2006a, b)

Mean Weighted Values: To discern the pattern of regional groups, ethnic groups, traditional occupational groups and linguistic groups using the frequency data, the mean weighted values of the trait has been calculated and estimates for the various groups are presented.

\section{FREQUENCY OF TASTE SENSITVITY AMONG INDIANS}

The frequency of allele $T$ among Indian populations is 0.457 (varies from 0.108 among Munda of Ranchi - Bihar to 0.912 in scheduled caste of Andhra Pradesh) which is little low as compared to Europeans but similar to that of Southwest Asian populations. The frequency is highest from the Islands zone as compared to rest of the zones of India-North (0.488), South (0.483), Central (0.389) and West (0.369) India. Among the population groups from Himalayan region mostly with Mongoloid affinities, the frequency is highest (0.533) as compared to NonHimalayan regions $(0.426)$. The frequency of allele $T$ is low in scheduled tribes (0.451) as compared to other groups with minor differences. It appears that populations with Mongoloid affinities possess high frequency of taster allele $(T)$ and quite high frequencies are observed among the Mongoloids of Asia as compared to Indian tribal groups among whom high frequencies of the nontaster allele $(t)$ are found. The frequency of allele $T$ is high from Islands natural region (0.547) and also from the Himalayan mountain complex region $(0.545)$, from where the frequency starts decreasing towards peninsular plateau. From the different climatic regions, the frequencies are high in polar, cold, humid and all monsoon type regions and is lowest in tropical savannah type region (0.377) (Bhasin et al. 1994; Bhasin and Walter 2001).

From East India, the frequency of allele $T$ is quite low from the states of Bihar $(0.298$, varies from 0.108 to 0.490$)$ and Orissa (0.324, ranges from 0.268 to 0.571 ) from where the frequencies are low among scheduled tribes as compared to rest of the ethnic groups, whereas from the states of Nagaland, Tripura, Meghalaya, Sikkim and Darjeeling district of West Bengal among the populations with Mongoloid affinities the frequencies are quite high $(0.702,0.597,0.580$, 0.694 and about 0.600 , respectively).

Similar high frequencies are observed from Western Himalayan region among populations with Mongoloid affinities from the states of Jammu and Kashmir (Ladakhis - 0.762), Himachal Pradesh (Gurkhas -0.615, Lahaulies - 0.643, Spitians - 0.654, Kinnaura - 0.606, Shipi - 0.662, Bodhs - 0.656, Savangalas - 0.626) and Uttar Pradesh - Central Himalayan region (different groups of Bhotias about 0.600 , Gurungs - 0.656 among others). The frequency of allele $T$ is also quite high among Newars; Sherpas and Tamangs combined; and Sherpas $(0.523,0.533$ and 0.719 , respectively) of Nepal and Tibetans (varies from 0.616 to 0.672 ) (For details see Bhasin et al. 1992).

The frequency of allele $T$ is low among 
scheduled tribes from Central India and it is almost similar among all the tribals except Dhurwa in which it is quite low (0.180). The frequency is quite high among different ethnic groups reported from South India (0.483, varies from 0.184 to 0.912 ) and it is highest among scheduled caste groups (0.662). The frequency of allele $T$ is highest among the population groups with Mongoloid affinities from the Himalayan region followed by South Indians.

From West India the frequency of allele $T$ is observed lowest (0.369, varies from 0.249 to 0.536 ) as compared to other zones and the frequencies are almost similar in both the states of Gujarat (0.368) and Maharashtra (0.371). Among the scheduled castes and scheduled tribes of West India (0.302 and 0.331 , respectively) the frequencies are lowest as compared to rest of the groups.

Among the Nicobarese with Mongoloid affinities the frequency of $T$ allele is high $(0.595)$ and from Andaman Islands, among Onges the frequency is 0.436 as compared to Bhantus, who had migrated from Uttar Pradesh (0.335).

In general, the frequency of taster allele $T$ is high among the population groups with Mongoloid affinities from the Himalayan region but lower than the Mongoloid populations from Far East and Southeast Asia and lowest among the scheduled tribes. The frequency of allele $T$ is low in West India and from there the frequency starts increasing in all the directions (Table 1, Fig. 1).

The allele frequency $T$ correlations with various climatic factors and altitude by different ethnic groups though showing significant differences are not high (Table 2).

Among the different occupational groups, the frequency of allele $T$ is almost similar among higher-priesthood (0.453), trade and commerce (0.459) and others - agriculture (0.481) and menial workers (0.474) groups, which indicates gene flow

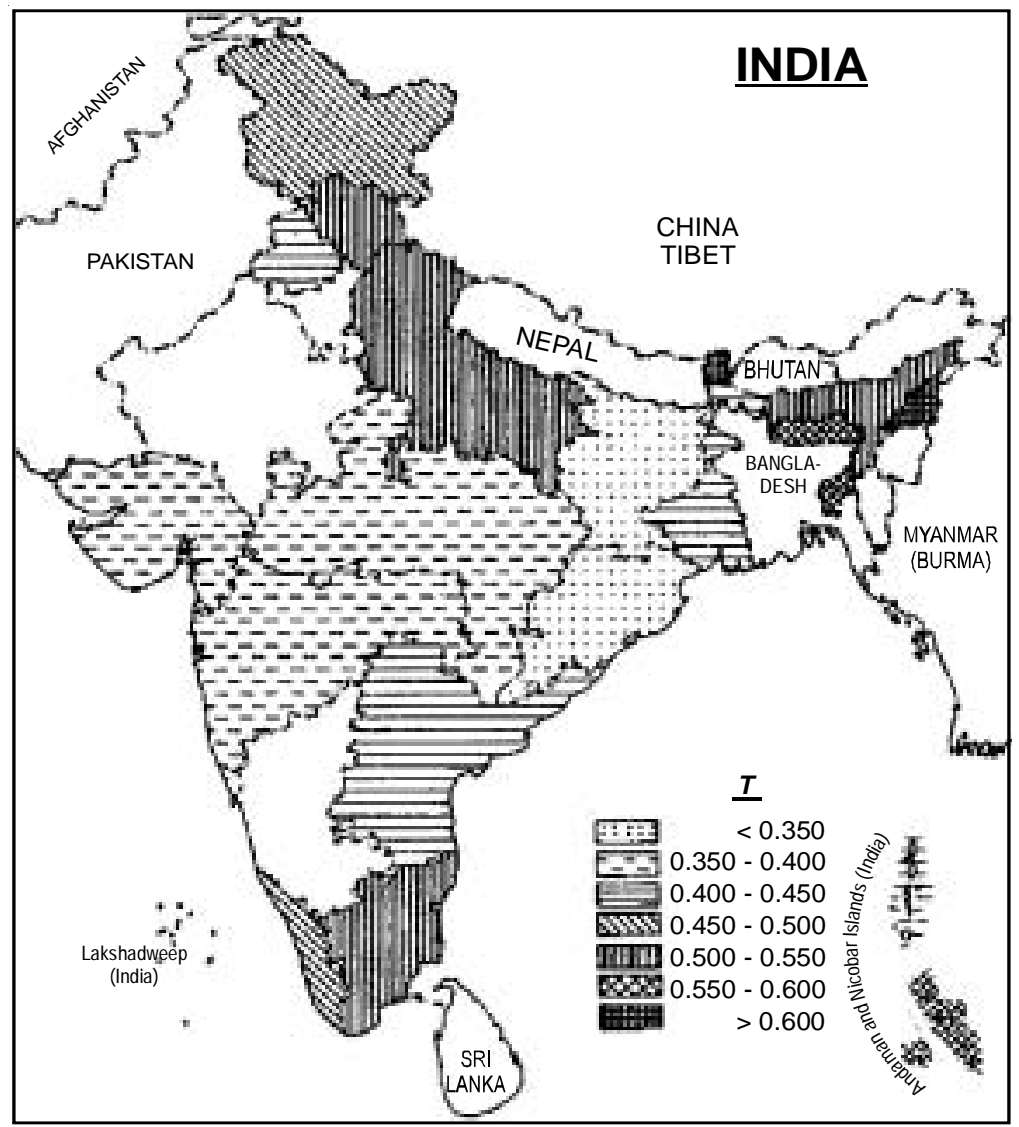

Fig. 1. Allele $T$ of taste sensitivity in different regions of India 

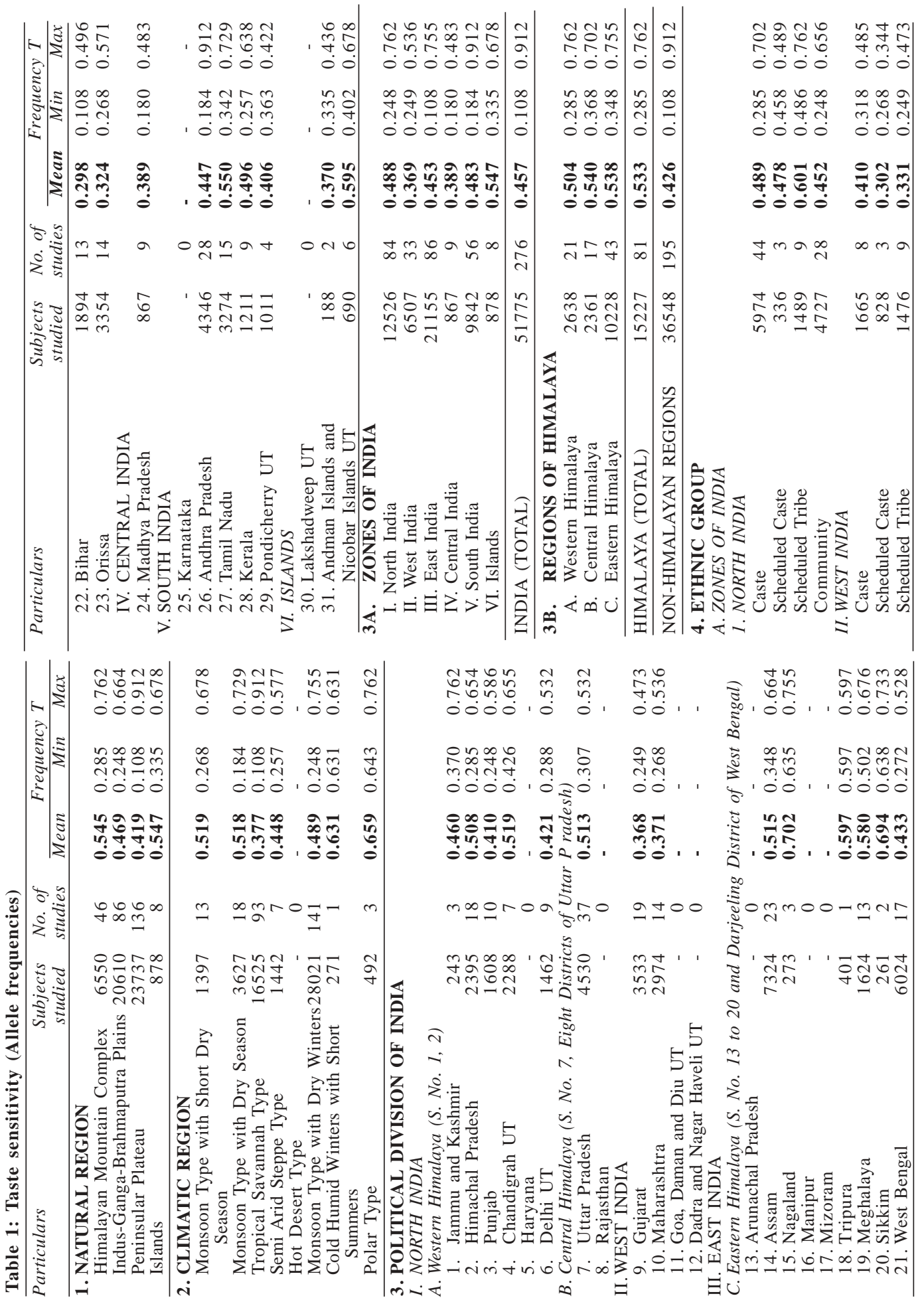


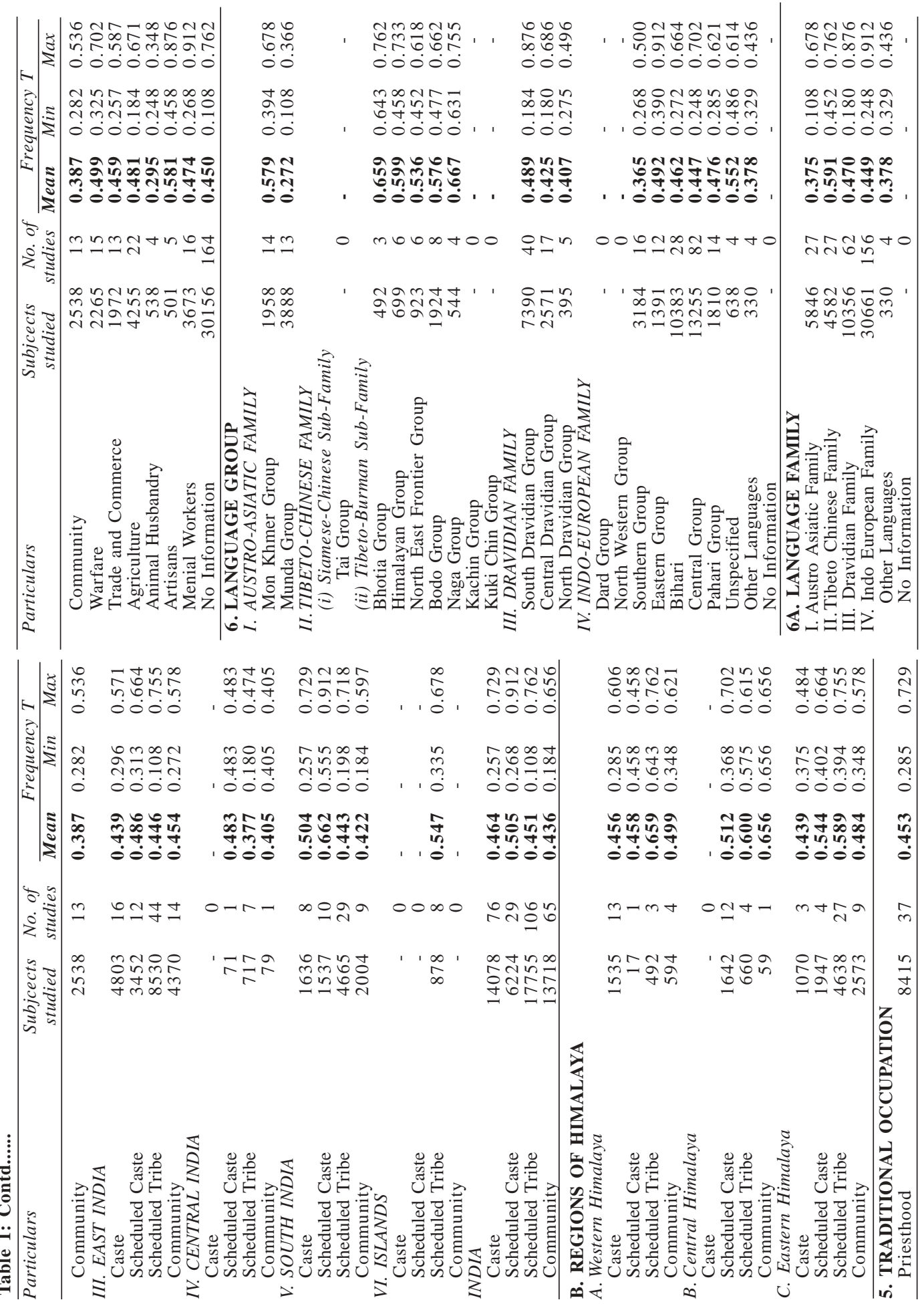


Table 2: Correlations with climatic factors and ethnic groups

\begin{tabular}{lc}
\hline Ethnic groups & $\begin{array}{c}\text { Taste } \\
\text { sensitivity } \\
T\end{array}$ \\
\hline Mean Annual Temperature & -0.222 \\
Caste & $0.413^{1}$ \\
Scheduled Caste & $-0.570^{3}$ \\
Scheduled Tribe & $-0.349^{2}$ \\
Community & $-0.326^{3}$ \\
\hline Total & \\
\hline Mean Annual Rainfall & -0.039 \\
Caste & $-0.477^{2}$ \\
Scheduled Caste & $0.460^{3}$ \\
Scheduled Tribe & 0.221 \\
Community & $0.189^{2}$ \\
\hline Total & \\
\hline Mean Annual Humidity & $-0.239^{1}$ \\
Caste & $0.498^{2}$ \\
Scheduled Caste & $0.400^{3}$ \\
Scheduled Tribe & 0.061 \\
Community & $0.206^{3}$ \\
\hline Total & \\
\hline Mean Altitude & $0.276^{1}$ \\
Caste & -0.249 \\
Scheduled Caste & $0.351^{3}$ \\
Scheduled Tribe & $0.276^{1}$ \\
\hline Community & $0.203^{3}$ \\
\hline Total & \\
\hline Significant at P &
\end{tabular}

1. Significant at $\mathrm{P}<0.05$

2. Significant at $\mathrm{P}<0.01$

3. Significant at $\mathrm{P}<0.001$

among them, as also observed for other genetic markers (Bhasin et al. 1994; Bhasin and Walter 2001).

Among the populations of Himalayan region with Mongoloid affinities, the frequency of allele $T$ is high in Mon Khmer group (0.579) of AustroAsiatic; in Bhotia group (0.659), Himalayan group (0.599), Bodo group (0.576), Naga group (0.667) of Tibeto-Chinese languages as compared to the speakers of Dravidian followed by IndoEuropeans and Munda group of Austro-Asiatic languages among whom the frequencies are low $(0.470,0.449$ and 0.272 , respectively) (Bhasin et al. 1994; Bhasin and Walter 2001).

Among population groups of India, the frequency of taster allele $T$ is 0.457 (varies between 0.108 and 0.912). From the different zones, it is present in high frequency among population groups of Islands followed by North and South India and is low in West and Central India, as well as among scheduled tribe groups in general. In Himalayan region, it frequency is high (0.533) as compared to Non-Himalayan region (0.426).
From Eastern Himalayn region, the frequency of allele $T$ is low (0.538) among populations with Mongoloid affinities as compared to the Mongoloid populations of East Asia and Southeast Asia (0.700) which may be due to high incidence of goiter in the former region (Bhasin et al. 1994). Among the speakers of various languages, the frequency is high in Austro-Asiatic (Mon Khmer) and Tibeto-Chinese speakers with Mongoloid affinities from Himalayan region and Nicobar Islands than in the speakers of Dravidian and Indo-European languages.

\section{REFERENCES}

Akesson HO 1959. Taste sensitivity to phenyl-thio-urea in tuberculosis and diabetes mellitus. Ann Hum Genet, 23: 262.

Azevedo EH, Krieger, MPM, Morton NE 1965. P.T.C. taste sensitivity and endemic goiter in Brazil. Am $J$ Hum Genet, 17: 87-90

Beiguelman B 1964. Taste sensitivity to phenylthiocarbamide among patients affected with both tuberculosis and leprosy. Acta Genet Med Gemell, 13: 190.

Bhasin MK 1988. Biology of the Peoples of Indian Region (Bangladesh, Bhutan, India, Maldives, Nepal, Pakistan, Sri Lanka). A Classified and Comprehensive Bibliography. Delhi: Kamla-Raj Enterprises.

Bhasin MK 2006a. Genetics of Castes and Tribes of India: Glucose -6- Phosphate Dehydrogenase Deficiency and Abnormal Haemoglobins ( $\mathrm{HbS}$ and $\mathrm{HbE}$ ). Int $J$ Hum Genet, 6: 49-72.

Bhasin MK 2006b. Genetics of Castes and Tribes of India: A Review of Population Differences in Red and Green Vision Deficiency in India. Int J Hum Genet, 6: 8188.

Bhasin MK, Walter H 2001. Genetics of Castes and Tribes of India. Delhi: Kamla-Raj Enterprises.

Bhasin MK, Walter H 2002. Genetics of Castes and Tribes of India: serum Protein Polymorphisms KM and GM Systems. Int J Hum Genet, 2: 119-138.

Bhasin MK, Walter H, Danker-Hopfe H 1992. The Ditribution of Genetical, Morphological and Behavioural Traits among the People of Indian Region (Bangladesh, Bhutan, India, Maldives, Nepal, Pakistan, Sri Lanka). Delhi: Kamla-Raj Enterprises.

Bhasin MK, Walter H, Danker-Hopfe H 1994. People of India. An Investigation of Biological Variability in Ecological, Ethno-Economic and Linguistic Group. Delhi: Kamla-Raj Enterprises.

Blakeslee AF, Salmon, MR 1931. Odour and taste blindness. Eugenical News, 16: 105-108.

Blakeslee AF, Salmon T N 1935. Genetics of sensory thresholds. Individuals taste reactions for different substances. Proc Natl Acad Sci, USA, 21: 84.

Blumberg B S 1961. Inherited susceptibility to disease. Arch Environ Health, 3: 612-636.

Boyd WC 1950. Genetics and Races of Man. Oxford: Blackwell. 
Boyd WC, Boyd LG 1937. Sexual and racial variations in ability to taste phenylthiocarbamide, with some data on inheritance. Ann Eugen, 8: 46.

Brachtel R, Walter H 1974. PTC-Schmeckfahigkeit und Psoriasis vulgaris. Anthrop Anz, 34: 231.

Chung CS, Witkop CJ, Henry JL 1964. A genetic study of dental caries with special reference to PTC taste sensitivity. Am J Hum Genet, 16: 231-245.

Cohen J, Ogden DP 1949. Taste blindness to PTC as a function of saliva. Science, 110: 532-533.

Das SR 1958. Inheritance of the P.T.C. taste character in man: An analysis of 126 Rarhi Brahmin families of West Bengal. Ann Hum Genet, 22: 200-212.

Das SR. 1966. Genetics of PTC taste character in man the incomplete dominance and penetrance of taste gene, pp. 250-258. In: Human Adaptability to Environments and Physical Fitness. M.S. Malhotra (Ed.). Defence Inst. Physiol. and Allied Sciences, Madras.

Falconer DS 1947. Sensory thresholds for solutions of phenylthiocarbamide. Ann Eugen, 13: 211-222.

Fox A 1932. The relationship between chemical constitution and taste. Proc Natl Acad Sci Washington, 18: 115-120.

Frazer GR 1961. Cretinism and taste sensitivity to phenylthiocarbamide. Lancet, 1: 964-965.

Glanville EV, Kaplan A R, Fischer R 1964. Age, sex and taste sensitivity. J Gerontol, 19: 474-478.

Harris H, Kalmus H 1949a. The measurement of taste sensitivity to P.T.C. Ann Eugen, 15: 24-31.

Harris H, Kalmus H. 1949b. Genetical differences in taste sensitivity to phenylthiourea and to anti-thyroid substances. Nature (Lond.), 163: 878.

Harris H, Kalmus H, Trotter WR 1949. Taste sensitivity to phenyl-thiourea ingoitre and diabetes. Lancet, ii: 1038-1039.

Hartmann G. 1939. Application of individual taste difference towards P.T.C. in genetic investigation. Ann Eugen, 10: 532.

Jörgensen G. 1969. Schemecken und Riechen. In: Handbuch der Humangenetik. Vol. 1/2, PE Becker
(Ed.). Stuttgart: Georg Thieme, Verlag. pp. 108-162.

Kalmus H 1958. Improvement in the classification of the tasters genotypes. Ann Hum Genet, 22: 222230 .

Kitchin FD, Howel-Evans W, Clarke CA, McConnell, RB and Sheppard P M 1959. P.T.C. taste response and thyroid disease. Brit Med J, i: 1069-1074.

Mohr J 1951. Taste sensitivity to phenylthiourea in Denmark. Ann Eugen, 16: 282-286.

Mourant AE, Kopec AC, Domaniewska-Sobczak K 1976. The Distribution of the Human Blood Groups and Other Polymorphisms. 2nd Edition, Oxford London: University Press.

Mouräo LACB, Salzano FM 1978. New data on the association between P.T.C. tasting and tuberculosis. Rev Brasil Biol, 38: 475.

Parr LW 1934. Taste blindness and race. J Hered, 25: 187-190.

Pons J 1955. Taste sensitivity to phenylthiourea in Spaniards. Hum Biol, 27: 153-160.

Roychoudhury AK, Nei M 1988. Human Polymorphic Genes. World Distribution. Oxford: Oxford University Press

Saldanha PH 1956. Apparent pleiotropic effect of gene determining taste threshold for P.T.C. Lancet, ii: 74.

Shepard TH, Gartler SM 1960. Increased incidence of non-tasters of phenylthiocarbamide among congenital athryreotic cretins. Science, 131: 929.

Stern C 1960. Principles of Human Genetics. San Francisco: W.H. Freeman.

Synder (1932) cited from Bhasin MK, Walter H, DankerHopfe H 1994. People of India. An Investigation of Biological Variability in Ecological, EthnoEconomic and Linguistic Group. Delhi: Kamla-Raj Enterprises.

Terry MC 1950. Taste blindness and diabetes in the coloured population of Jamaica. J Hered, 41: 305307.

Terry MC, Segall G 1947. The association of diabetes taste blindness. J Hered, 38: 135-137. 